\title{
A influência do conhecimento prévio no ensino de Física Moderna e Contemporânea: um relato de mudança conceitual como processo de aprendizagem significativa
}

Alex Lino

Polônia Altoé Fusinato

\section{Resumo}

Este trabalho buscou verificar se o ensino de Física Moderna e Contemporânea no Ensino Médio pode ser potencialmente significativo quando inserido de forma conjunta com o ensino de Física Clássica. Os assuntos que foram trabalhados, com alunos da segunda série do Ensino Médio de uma escola da cidade de Paraguaçu Paulista, têm em comum os conceitos de calor e energia. Durante as aulas de processos de transferência de calor foi abordado o problema da radiação de corpo negro, inserindo conceitos de Física Quântica, como a quantização de energia. As aulas foram preparadas com base na teoria de Aprendizagem Significativa de David Ausubel e incluídas na grade da disciplina Física durante o primeiro semestre letivo do ano de 2010. As análises dos questionários revelaram que muitos alunos sofreram obliteração de seus subsunçores e os mapas nos mostraram hierarquias altamente organizadas das estruturas cognitivas dos alunos, que são indícios de aprendizagem significativa.

Palavras-chave: Física Moderna e Contemporânea, Aprendizagem Significativa, Mapas Conceituais.

\footnotetext{
Abstract

The influence of prior knowledge in the teaching of Modern and Contemporary Physics: an account of conceptual change as a process of meaningful learning

This Research aimed verify if the teaching of Modern and Contemporary Physics at high school may be potentially significant when inserted in a combined way with the teaching of Classical physics. The topics that were studied with the second year students of a high school from Paraguaçu Paulista have in common
} 
the concepts of heat and energy. During the classes concerning the process of heat transference, it was approached the issue about the blackbody radiation problem, inserting concepts of Quantum Physics, such as the quantization of energy. In order to reach this objective, the classes were prepared based on the theory of significant learning of David Ausubel and included into the schedule of the Physics discipline during the first semester in the year of 2010. The analysis of the questionnaires reveled that many of the students suffered obliteration of their subsumers and the maps shows us highly organized hierarchies of the cognitive structures of the students, this is an indication of significant learning. It was also observed, mainly through the analysis of the conceptual maps, relation between classical physics and Concepts of Modern physics.

Keywords: Modern and Contemporary Physics, Significant Learning, Conceptual Maps.

\section{Introdução}

As questões que envolvem a aprendizagem de conteúdos de Física Moderna e Contemporânea (FMC) no Ensino Médio (EM) têm sido fonte de pesquisa no Brasil desde os primeiros anos da década de 1990 (TERRAZZAN, 1994) e alguns trabalhos, tais como os de Cabral de Paulo $(1997,2006)$, Fischler e Lichtfeldt (2002), são dois exemplos dos poucos trabalhos que se dedicam à compreensão da aprendizagem desses conceitos na perspectiva da cognição.

Para Terrazzan (1992) a necessidade de se atualizar o currículo de Física justifica-se pela influência crescente dos conteúdos contemporâneos (inicio do século XX até inicio do século XXI) para o entendimento do universo criado pelo mundo atual, bem como a necessidade de formar um cidadão consciente e participativo que atue nesse mesmo ambiente.

A importância do tema ainda pode ser justificada de forma clara nos Parâmetros Curriculares Nacionais do Ensino Médio (PCNEM), afirmando que a Física deve apresentar-se como um conjunto de competências específicas com o objetivo de que o aluno perceba e lide com os fenômenos naturais e tecnológicos, presentes tanto no cotidiano mais imediato quanto na compreensão do Universo distante, a partir de princípios, leis e modelos que são construídos pela própria Física. (BRASIL, 2002)

E é deste cotidiano que o aluno adquire seus conhecimentos prévios que são levados para dentro da sala de aula no momento do aprendizado, que como veremos mais adiante são muito significativos para a sua aprendizagem. 
Em contrapartida, muitos fatores contribuem para a falta deste tipo de conhecimento nas escolas, como por exemplo, a escassez de material didático e metodologias que dificultam o trabalho dos professores frente à sala de aula, mas ainda assim afirmamos que, dentre essas muitas pesquisas realizadas sobre a temática, poucas são as que se preocupam com a investigação dos fatores que determinam a aprendizagem dos conceitos básicos de FMC por alunos do EM.

Uma revisão bibliográfica sobre a área de pesquisa relacionada à $\mathrm{FM}$ foi realizada por Ostermann e Moreira (2000), em que, a partir de uma consulta a artigos em revistas, livros didáticos, dissertações, teses, projetos e navegações pela Internet, relacionados ao assunto inserção de FM no Ensino Médio (EM), consideraram três vertentes representativas de abordagens metodológicas para a introdução de Física Moderna e Contemporânea (FMC) no EM:

1. exploração dos limites dos modelos clássicos;

2. não utilização de referências aos modelos clássicos;

3. escolha de tópicos essenciais de FMC.

A primeira vertente explora os limites da Física Clássica (FC) para a inserção de FMC, quando os modelos da FC não explicam determinado fenômeno podemos inserir a FMC para a explicação do respectivo fenômeno. A segunda vertente nos tenta mostrar a possibilidade de inserção de FMC sem referência a FC, ou seja, nos tenta mostrar que é possível ensinar FMC sem a ligação com a FC. E por fim, a terceira vertente escolhe alguns tópicos de FMC para serem abordados no EM, em geral, ao final do estudo costumeiro dos tópicos, que são ditos essenciais, de FC.

Estas vertentes são as mais utilizadas nas pesquisas acerca da inserção de FMC no EM como propostas e solução dos muitos problemas que são enfrentados.

Ainda no texto de Ostermann e Moreira, eles concluem o seguinte:

Parece que há muitas justificativas em favor da atualização curricular e até uma bibliografia que apresenta (não tão aridamente como a literatura especializada) temas modernos. Entretanto, colocar todas estas reflexões na prática da sala de aula é ainda um desafio. Outra questão desafiadora é a escolha de quais tópicos de FMC deveriam ser ensinados nas escolas [...] (OSTERMANN E MOREIRA, 2000).

Sendo assim, a partir dos parâmetros de necessidade considerados anteriormente e da já relatada escassez de trabalhos sobre aprendizagem de FMC no EM, desenvolveu-se uma pesquisa que visa exatamente aplicar tópicos de FMC em sala de aula, apresentando resultados de aprendizagem, ou seja, avaliar e propor uma metodologia diferenciada de aplicação de conteúdos de FMC baseada na teoria da aprendizagem significativa de David Ausubel.

R. B. E. C. T., vol 4, núm 3, set./dez. $2011 \quad$ ISSN - 1982-873X 
Para o desenvolvimento do trabalho, escolheu-se uma turma da segunda série do Ensino Médio, na qual os conteúdos de quantização da energia de Planck foram introduzidos a partir do estudo da radiação térmica, em termodinâmica. Com isto, pôde-se avaliar a qualidade da aprendizagem destes conceitos por meio dos preceitos teóricos da Aprendizagem Significativa, recorrendo à utilização de questionários e à confeç̧ão de mapas conceituais pelos alunos como forma de avaliação.

Estas aulas foram preparadas adotando-se como referencial a teoria da aprendizagem significativa, levamos em consideração momentos da aprendizagem em que o conhecimento prévio poderia intervir no sentido de auxiliar a aprendizagem subseqüente, tornando a aprendizagem significativa.

\section{Aprendizagem Significativa}

David Ausubel publicou seus primeiros estudos sobre a teoria da aprendizagem significativa em 1963 (The Psychology of Meaningful Verbal Learning) e desenvolveu-a durante as décadas de 1960 e 1970. Mais tarde, no final da década de 1970, Ausubel recebeu a contribuição de Joseph D. Novak que progressivamente incumbiu-se de refinar e divulgar a teoria. Com a contribuição de Novak, a teoria da aprendizagem significativa modificou o foco do ensino.

Desde a década de 1970, a teoria tem sido enriquecida, interpretada e divulgada por Marco Antonio Moreira e Elcie F. Salzano Masini, entre outros, aqui no Brasil.

O que Ausubel mais enfatiza em sua teoria é ensinar a partir do que o aluno já sabe; em suas próprias palavras:

"o mais importante fator isolado que influencia a aprendizagem é o que o aprendiz já sabe. Determine isto e ensine-o de acordo" (Ausubel, 1980, p. 6).

Assim, deve-se primeiramente dar atenção àquilo que o aluno já sabe, para assim, ser planejado as situações de aprendizagens subseqüentes.

Estas idéias iniciais trazidas pelo aluno, para a sala de aula, podem ser decisivas durante a aprendizagem. Se os conceitos a serem aprendidos forem ligados, incorporados ou relacionados (isto quer dizer assimilação) com o conhecimento já existente, estes conhecimentos vão adquirir significados, tanto o conhecimento já existente como o conhecimento a ser assimilado. $O$ novo passa a ter significados para o indivíduo e o prévio adquire novos significados, fica mais diferenciado, elaborado (Masini \& Moreira, 2008, p.16). Isto é aprendizagem significativa, aprendizagem com incorporação de significados. 
No entanto, para ocorrer aprendizagem significativa, ou seja, para existir a ligação entre os conhecimentos, devem existir, a priori, algumas condições. As condições de ocorrência de aprendizagem significativa são:

...(1) que o próprio material de aprendizagem possa estar relacionado de forma não arbitraria (plausível, sensivel e não aleatória) e não literal com qualquer estrutura cognitiva apropriada e relevante (i.e., que possui significado 'lógico') e (2) que a estrutura cognitiva particular do aprendiz contenha ideias ancoradas relevantes, com as quais se possam relacionar o novo material (Ausubel, 2002, p.1).

Com relação a primeira condição, para assimilar significativamente um conceito o estudante deve primeiramente querer aprender, deve construir uma necessidade de mexer com seu conhecimento prévio, uma vez que será este conhecimento resgatador dos novos conhecimentos. Deve também perceber o potencial do novo conceito, incluindo seu significado, sua importância, suas aplicações e suas correlações com outros conceitos já existentes na estrutura cognitiva.

Uma vez existindo a predisposição em aprender, a interação que ocorre entre o conceito prévio e o novo conceito aprendido não deve ocorrer de qualquer forma, ou seja, não deve ser arbitrária, ligada ou assimilada a qualquer conceito, mas sim a conceitos relevantes existentes na estrutura cognitiva do indivíduo (estrutura de conhecimento).

Este conceito relevante na estrutura cognitiva do individuo é denominado por Ausubel de conceito subsunçor, que tem o papel de "ancoragem" dos conceitos novos a serem aprendidos. Assim, o conceito subsunçor "ancora" o novo conhecimento na estrutura cognitiva. Este processo de ancoragem é conhecido como processo de assimilação.

Estas interações também não devem ser literais, isto significa que a assimilação não deve ocorrer ao pé-da-letra. No momento da assimilação, o novo conhecimento adquire significados, que podem ser de dois tipos: significados denotativos e conotativos. Os significados denotativos são atribuídos ao contexto de uma disciplina, de uma área de conhecimento ou de um uso comum de conhecimentos entre diversos indivíduos. Já os significados conotativos são do próprio sujeito, ou seja, são valores pessoais que o individuo atribui ao significado dos conceitos ou eventos.

Quando o indivíduo aprende significativamente um conceito, ele pode externalizá-lo por meio de uma dissertação ou uma apresentação oral. Neste momento, a externalização não ocorre de modo literal aos significados denotativos do conceito, mas com significados idiossincráticos. Aqui, existe a possibilidade de identificar tais significados conotativos e diferenciá-los dos denotativos. 
A segunda condição para aprendizagem significativa é que o material ou a situação a ser apresentada ao aprendiz deve ser potencialmente significativa, ou seja, deve permitir que existam fluxos de relações entre conceitos prévios e conceitos novos.

O papel do professor, neste caso, é selecionar materiais de potenciais mais significativos aos alunos, ou seja, assuntos que tenham grande potencial de ligação com os conhecimentos prévios destes. Uma seqüência de estudo deve ser preparada e planejada pelo professor a fim de contribuir para tais relações (nova informação relacionada à estrutura antiga).

É errado dizer que um material educativo é significativo. Não tem sentido dizer, por exemplo, que um livro é significativo ou que uma aula é significativa. Os significados não estão nos materiais educativos. Eles estão nos alunos, nos professores, nos autores. Os materiais são apenas potencialmente significativos. E isso implica que tenham significados lógicos e que os aprendizes tenham conhecimentos prévios especificamente relevantes (Masini \& Moreira, 2008, p.19).

Quando ocorre a aprendizagem significativa ocorrem dois processos na estrutura cognitiva do aprendiz, a diferenciação progressiva e a reconciliação integrativa que são dois meios dinâmicos da estrutura cognitiva que ocorrem à medida que acontecem as assimilações.

A diferenciação progressiva é o processo que ocorre devido a assimilações de conhecimentos novos na estrutura cognitiva pelo subsunçor. À medida que o mesmo subsunçor incorpora novos conhecimentos ele vai ficando cada vez mais diferenciado dentro da estrutura cognitiva. Diferenciado no sentido de significados, relativamente, a outros conceitos dentro da própria estrutura cognitiva. A diferenciação de conceitos pode facilitar a distinção entre significados, podendo assim, evitar confusões a respeito de assimilações de conceitos novos a subsunçores não correspondentes a estes.

Para evitar algum tipo de perda de significados existe a reconciliação integrativa, que tem o papel fundamental de relacionar estruturas de conhecimentos que são aparentemente distintas.

Levando estes fatores iniciais em consideração o professor pode criar estratégias para a facilitação da ocorrência de aprendizagem significativa. Uma das estratégias que o professor pode utilizar é a que leva em consideração a diferenciação progressiva e a reconciliação integrativa. Esta estratégia é gerada durante a preparação do material potencialmente significativo que deve ser apresentado ao aluno, via aprendizagem receptora ${ }^{1}$. As idéias mais gerais e inclusivas devem

${ }^{1}$ A aprendizagem por recepção significativa envolve, principalmente, a aquisição de novos significados a partir de material de aprendizagem apresentado (Ausubel, 2002, p.1). 
ser apresentadas no início do conteúdo e, progressivamente, estas idéias devem ser detalhadas e especificadas.

Ao propor isso, Ausubel baseia-se em duas hipóteses: a) é mais fácil para o ser humano captar aspectos diferenciados de um todo mais inclusivo previamente aprendido, do que chegar ao todo mais inclusivo a partir de suas partes diferenciadas; b) a organização do conteúdo de uma certa disciplina, na mente de um indivíduo, é uma estrutura hierárquica na qual as idéias mais inclusivas estão no topo da estrutura e, progressivamente, incorporam proposições, conceitos e fatos menos inclusivos e mais diferenciados (Moreira \& Masini, 1982, p.21).

Como também já foi mencionado, deve acontecer a reconciliação integrativa, ou seja, os conhecimentos adquiridos devem ter relações em estruturas mais complexas ou mesmo entre conhecimentos ancorados por um mesmo subsunçor. Aqui, o papel da linguagem é o principal facilitador para a ocorrência deste tipo de ligação. Linguagem no sentido de interação entre professor e aluno para o estabelecimento de significados.

Os organizadores prévios também podem servir para focalizar a atenção do aprendiz em elementos de materiais de estudo que poderiam passar inteiramente despercebidos sem induzir a disposição que pode por eles ser oferecida. Os organizadores prévios se referem a uma organização inicial de conceitos que já foram estudados em um momento passado e que serão essenciais ao aprendizado significativo do aprendiz no momento presente (Novak, 1981).

Evidenciar se o aluno obteve aprendizagem significativa não implica em pedir ao aluno respostas mecanicamente memorizadas com testes que atribuam conceitos ou elementos essenciais de uma proposição de conteúdo, ou seja, pedir ao aluno para que reproduza idéias no mesmo sentido das palavras que foram originalmente apresentadas.

Levando em consideração que a aprendizagem significativa deve-se apresentar de maneira não arbitraria e não substantiva ou não literal, as avaliações para evidenciar aprendizagens significativas também devem tender por estas premissas. Quando o aluno aprende significativamente, ele atribui tanto significados denotativos que são universais, quanto significados conotativos que são do próprio sujeito, idiossincráticos. Desta forma, no momento em que o aluno externaliza estes conhecimentos, os significados não são literais, ou seja, não são ao pé-da-letra, não são iguais em todos os sentidos ao apresentado pelo professor, mas sim com significados conotativos, do próprio aluno.

Levando estes pontos em consideração, existe a possibilidade de evidenciar se houve aprendizagem significativa por parte do aluno.

Tanto para a facilitação da aprendizagem significativa como para evidenciar se houve aprendizagem significativa, os mapas conceituais podem ser utilizados. Por estas perspectivas R. B. E. C. T., vol 4, núm 3, set./dez. 2011 
serão abordadas as idéias de mapas conceituais, como utilizá-los, construí-los, aplicá-los e avaliálos.

Mapa conceitual é um tipo de diagrama que indica relações entre conceitos ou entre palavras que usamos para representar os conceitos. Estes conceitos são especificados em caixas que podem ser, por exemplo, triângulos, retângulos ou círculos, que também podem estar interligados por linhas ou setas quando entre eles existir alguma relação, rotulando essa ligação, especificando de que forma esses conceitos estão relacionados.

Os mapas conceituais têm por objetivo representar as relações significativas entre conceitos em forma de proposições, quando é terminada uma tarefa de aprendizagem eles podem proporcionar um resumo esquemático de tudo o que foi aprendido (NOVAK \& GOWIN, 1988, p.33).

A estrutura cognitiva é hierárquica em termos de generalizações conceituais, ou seja, conceitos mais gerais ocupam o topo da estrutura, seguidos por conceitos cada vez mais específicos, ocupando lugares cada vez mais abaixo da mesma estrutura. Como os mapas representam uma estrutura de aprendizado, eles devem seguir a mesma linha de pensamento.

A elaboração de mapas conceituais é uma técnica destinada para externalizar os significados dos conceitos e proposições do indivíduo. Neste sentido, a frequente elaboração destes pode ser uma atividade criativa e pode ajudar a fomentar a criatividade. Durante a confecção dos mapas, o individuo também pode perceber relações entre conceitos que antes não percebia, gerando assim, novas proposições significativas (NOVAK \& GOWIN, 1988, p. 34-35).

Desta forma, o professor pode utilizar os mapas conceituais para determinar o caminho que deve seguir para negociar os significados e organizá-los com os alunos, assim como ensinar as concepções equivocadas que podem ter. Para isso deve-se, inicialmente, ensinar os alunos a confeccionar mapas.

Apesar de os mapas conceituais serem uma ferramenta muito importante para analise de aprendizagem significativa, eles não mostram uma representação por completa dos conceitos existentes na estrutura cognitiva do aluno, mas proposições relevantes que o aluno conhece e mostra ao professor. Isto se torna muito importante para a negociação de significados entre professor e aluno, fazendo com que o professor identifique as limitações ou obstáculos que os alunos possuem como bloqueio de aprendizagem. Assim, pela negociação, o professor pode mostrar o caminho que o aluno deve seguir para encontrar o entendimento significativo do que se estuda.

Com isso, conclui-se que a teoria da aprendizagem significativa pode ser utilizada como um parâmetro bem fundamentado no estudo da aprendizagem de conceitos. 


\section{Metodologia}

A pesquisa foi desenvolvida no próprio ambiente escolar, local onde os alunos estão acostumados a conviver com o aprendizado, e também no horário comum das aulas em uma escola da rede particular de ensino situada na cidade de Paraguaçu Paulista - SP.

A série escolhida para a aplicação do projeto foi a 2ª série do $E M$, uma vez que os temas escolhidos foram idealizados segundo o planejamento de conteúdos desta mesma série.

Escolheu-se como tema uma aula em que houvesse algum problema fenomenológico no qual a FC não daria conta de explicar. Sendo assim, teria de haver a necessidade de explicação seguindo algum modelo de FMC. Desta forma escolheu-se como problema a ser tratado "a radiação de corpo negro", inserida dentro do tema "mecanismos de transferência de calor". Como a interpretação clássica não explica a curva espectral da radiação de corpo negro deve-se considerar as propostas dos modelos da Física Quântica (FQ), que propõe a quantização da energia para a solução do problema. Desta forma, será mostrado, a seguir, como foi inserido o problema da radiação de corpo negro e a solução do problema com a quantização da energia. Para isto seguiu-se alguns princípios da teoria da aprendizagem significativa de David Ausubel.

Para a aprendizagem significativa foi levado em consideração, inicialmente, a premissa de que o material que deveria ser apresentado para os alunos fosse potencialmente significativo, ou seja, que este material permitisse que os alunos estabelecessem as relações existentes entre os conceitos prévios e os novos conceitos a serem aprendidos. Outro ponto importante da preparação, que levou-se em consideração, foi o de que pode-se perceber os significados dos conceitos mais facilmente quando o material é apresentado partindo de conceitos mais gerais e progressivamente especificando-os.

Para atingir estes objetivos criou-se uma hierarquia conceitual da aula relativamente à especificidade das idéias que seriam apresentadas. Como a teoria de Ausubel orienta, deve-se sempre seguir esta hierarquia conceitual durante as aulas, mas também sempre voltando a conceitos já apresentados para desta forma fazer com que o aluno perceba as relações existentes entre os conceitos, que caracteriza uma estratégia de ensino para a facilitação de aprendizagem significativa, a diferenciação progressiva e a reconciliação integrativa. O procedimento bem como o cronograma planejados são apresentadas no quadro 1 , juntamente com a divisão da carga horária. 


\begin{tabular}{|c|c|c|}
\hline Conteúdo & Objetivos & Aula \\
\hline Energia & $\begin{array}{l}\text { Construir uma idéia mais geral de energia, inserindo fatos } \\
\text { históricos e algumas aplicações. }\end{array}$ & 1 e 2 \\
\hline Calor parte I & $\begin{array}{l}\text { Desenvolver o conceito de calor, mostrando ao aluno } \\
\text { como este conceito é utilizado de forma equivocada em } \\
\text { nosso cotidiano. }\end{array}$ & 1 e 2 \\
\hline Calor parte II & $\begin{array}{l}\text { Desenvolver o conceito correto de calor, com exemplos } \\
\text { de fenômenos que ocorrem devido a transferência de } \\
\text { energia entre corpos a diferentes temperaturas. }\end{array}$ & 1 e 2 \\
\hline $\begin{array}{l}\text { Transferência de calor por } \\
\text { condução }\end{array}$ & Explicar o processo de condução de calor. & 1 e 2 \\
\hline $\begin{array}{l}\text { Transferência de calor por } \\
\text { convecção }\end{array}$ & $\begin{array}{l}\text { Explicar o processo de convecção. } \\
\text { Explicar a convecção na água entre } 0^{\circ} \mathrm{C} \mathrm{e} 4^{\circ} \mathrm{C} \text {. }\end{array}$ & 1 e 2 \\
\hline $\begin{array}{l}\text { Transferência de calor por } \\
\text { irradiação }\end{array}$ & $\begin{array}{l}\text { Explicar o processo de irradiação. } \\
\text { Mostrar que todos os corpos emitem radiação, seja } \\
\text { radiação visível ou não visível }\end{array}$ & 1 e 2 \\
\hline $\begin{array}{l}\text { Ondas eletromagnéticas } \\
\text { parte I }\end{array}$ & $\begin{array}{l}\text { Desenvolver uma ideia geral do que são ondas } \\
\text { eletromagnéticas. }\end{array}$ & 3 e 4 \\
\hline $\begin{array}{l}\text { Ondas eletromagnéticas } \\
\text { parte II }\end{array}$ & $\begin{array}{l}\text { Desenvolver as propriedades, as características, os tipos e } \\
\text { a constituição, assim como o espectro eletromagnético. }\end{array}$ & 3 e 4 \\
\hline Emissão e absorção térmica & $\begin{array}{l}\text { Explicar de forma clássica como acontece a emissão e a } \\
\text { absorção de radiação. }\end{array}$ & 3 e 4 \\
\hline Corpo negro & Construir a ideia de corpo negro ideal e corpo negro real. & 3 e 4 \\
\hline Descoberta de Kirchhoff & $\begin{array}{l}\text { Construir a ideia de que a radiação é a mesma para vários } \\
\text { corpos em equilíbrio térmico }\end{array}$ & 3 e 4 \\
\hline $\begin{array}{l}\text { Experimento da radiação de } \\
\text { cavidade }\end{array}$ & $\begin{array}{l}\text { Desenvolver a idéia de como foi realizada a experiência da } \\
\text { radiação de corpo negro, e como foi obtida a curva } \\
\text { experimental da intensidade da radiação por sua } \\
\text { freqüência dependente da temperatura do corpo. }\end{array}$ & 5 e 6 \\
\hline Deslocamento de Wien & Relacionar a temperatura do corpo com a freqüência da & 5 e 6 \\
\hline
\end{tabular}




\begin{tabular}{|l|l|l|}
\hline & radiação liberada. & 5 e 6 \\
\hline $\begin{array}{l}\text { Espectro da luz solar e a visão } \\
\text { humana }\end{array}$ & Explicar a lei do deslocamento de Wien & 7 \\
\hline $\begin{array}{l}\text { Tentativas de descrever e } \\
\text { quantificar o experimento da } \\
\text { radiação de corpo negro }\end{array}$ & $\begin{array}{l}\text { Desenvolver alguns modelos e teorias que falharam ao } \\
\text { tenterever a radiação de corpo negro. }\end{array}$ & e \\
\hline $\begin{array}{l}\text { A quantização da energia de } \\
\text { Planck }\end{array}$ & $\begin{array}{l}\text { Desenvolver a solução do fenômeno apresentada por } \\
\text { Planck. }\end{array}$ & 7 e 8 \\
\hline $\begin{array}{l}\text { Quantização da energia } \\
\text { Desenvolver a equação da quantização da energia que } \\
\text { relaciona energia com a freqüência da radiação. }\end{array}$ & 7 e 8 \\
\hline $\begin{array}{l}\text { Algumas da } \\
\text { quantização de energia }\end{array}$ & $\begin{array}{l}\text { Desenvolver o significado da constante de Planck e que, } \\
\text { por ter valor muito pequeno, é difícil observarmos os } \\
\text { fenômenos quânticos macroscopicamente. }\end{array}$ & 7 e 8 \\
\hline
\end{tabular}

Quadro 1 - Organização da exposição dos assuntos no desenvolvimento do projeto

A estrutura hierárquica pode ser mais facilmente percebida na seguinte figura:

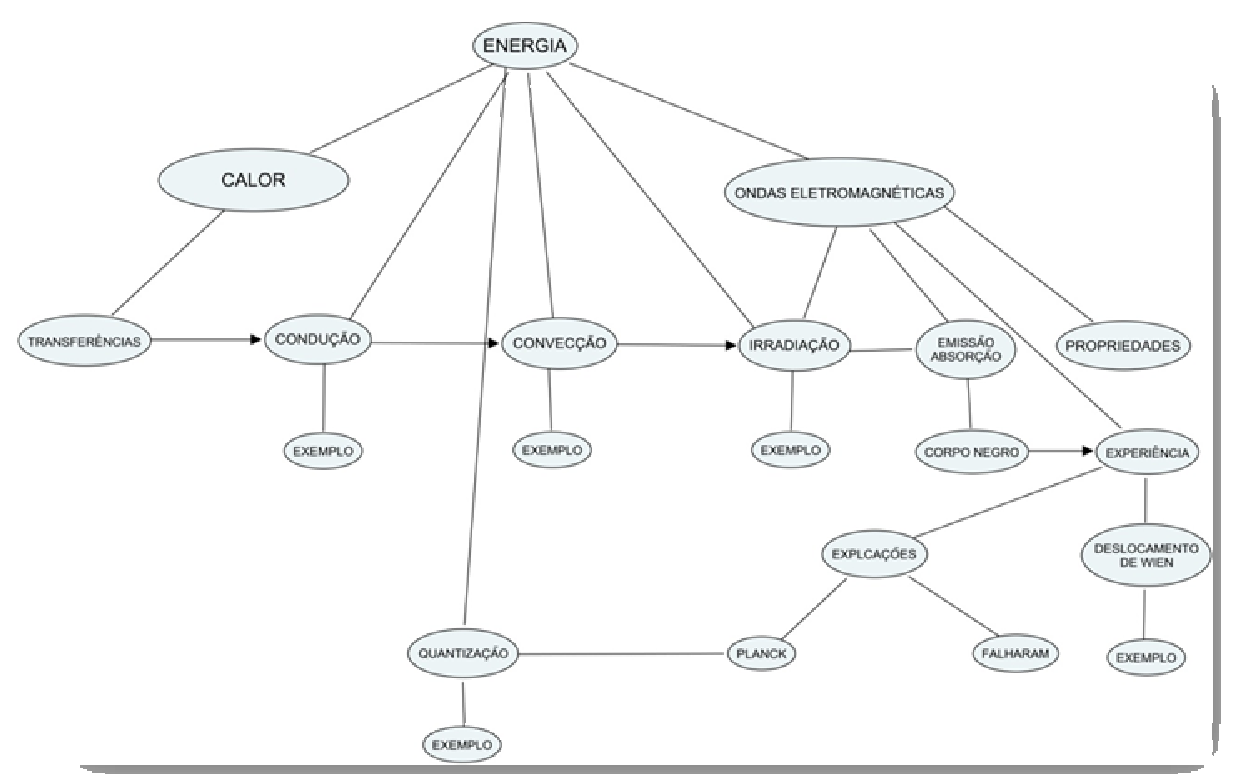

Figura 1 - Organização conceitual da programação do conteúdo

Esta figura nos dá uma ideia mais geral da organização conceitual para a programação do conteúdo; aqui, foram identificados os conceitos básicos da tarefa de ensino e de como eles são estruturados. Com o problema organizacional resolvido, pode-se dar atenção à preparação da aula utilizando as estratégias de ensino para a facilitação da aprendizagem significativa. Para 
tanto, utilizou-se dos princípios da diferenciação progressiva, da reconciliação integrativa e dos organizadores prévios.

Para exemplificar como essas considerações da teorias foram levadas à prática de sala de aula, quando se começou a apresentar o conceito de energia no inicio das aulas, sempre se fazia referência a esse conceito nos assuntos de calor e de ondas eletromagnéticas, assim como no final, em quantização da energia. Desta forma, os conceitos puderam se interrelacionar, adquirindo significados mais abrangentes, modificando os subsunçores e facilitando a aprendizagem significativa.

Em relação aos organizadores prévios, utilizou-se esta técnica sempre na introdução das aulas. Este processo permitiu reorganizar os conceitos prévios para a introdução das novas idéias que foram apresentadas. $\mathrm{Na}$ introdução das aulas foram reorganizadas as idéias já apresentadas anteriormente, e assim, em todas as aulas. Esta forma de abordagem prepara os subsunçores para as assimilações dos novos conceitos, ou até mesmo pode servir como momento de formação dos subsunçores, muito importante para o processo de aprendizagem significativa.

Resumida e objetivamente, seguimos uma linha de construção racional, reflexão das experiências e dos fenômenos, tomando cuidado com analogias e imagens metafóricas, que utilizamos apenas após a apresentação dos fenômenos. Evitamos explicações exageradas em sentidos metafísicos e mostramos a importância dos dados quantitativos e qualitativos

Por exemplo, em relação à reflexão das experiências, tomamos cuidado para que acontecesse reflexão principalmente na experiência de radiação de corpo negro, momento muito importante para o estudo. Para isto, fizemos algumas perguntas aos alunos sobre a experiência que foi mostrada por meio de uma simulação com titulo "radiação de corpo negro", retirado do Banco Internacional de objetos Educacionais ${ }^{1}$ (BIOE). Também foram levantadas questões sobre os problemas de radiação de corpo negro, que deveriam ser respondidas pelos alunos no momento das aulas.

Os cuidados que tomamos com as analogias foram, principalmente, no momento de estudo da quantização da energia, momento este em que poderiam aparecer alguns termos como "pacotes de energia" ou "pacotinhos de energia", explicamos aos alunos o real conceito de quantização de energia, e após isto, inserimos a analogia dos "pacotes de energia". Já a importância dos dados quantitativos e qualitativos, foi mostrada também no momento de estudo

\footnotetext{
${ }^{1}$ Encontrada no endereço eletrônico http://objetoseducacionais2.mec.gov.br/handle/mec/9393.
} 
da quantização da energia, em que abordamos os conceitos de quantização por meio das soluções quantitativas apresentadas por Planck, e as interpretações qualitativas de quantização apresentadas por Einstein, de maneira simplificada e com a matemática adequada para alunos de EM.

Para conseguir atingir um dos objetivos deste trabalho em relação à verificação de ocorrência de aprendizagem significativa optou-se, como método de avaliação, pelos mapas conceituais. Para tanto, deveria ser ensinado, primeiramente, os alunos a construírem os mapas. Desta forma, antes da aplicação das aulas elaboradas, reservou-se duas aulas com este intuito.

Após a aula, solicitou-se aos alunos que confeccionassem um mapa como exercício. Distribuiu-se um texto sobre o funcionamento de uma usina hidroelétrica, solicitou-se que grifassem todos os conceitos mais importantes do texto, escrevessem esses conceitos em uma folha, identificando a ordem de generalização de cada conceito, para que assim pudessem construir os mapas conceituais. $O$ texto utilizado na aula referente a construção dos mapas teve $o$ seguinte titulo: "O funcionamento de uma usina hidroelétrica".

Um exemplo de mapa conceitual feito por um aluno que participou do projeto pode ser observado em seguida:

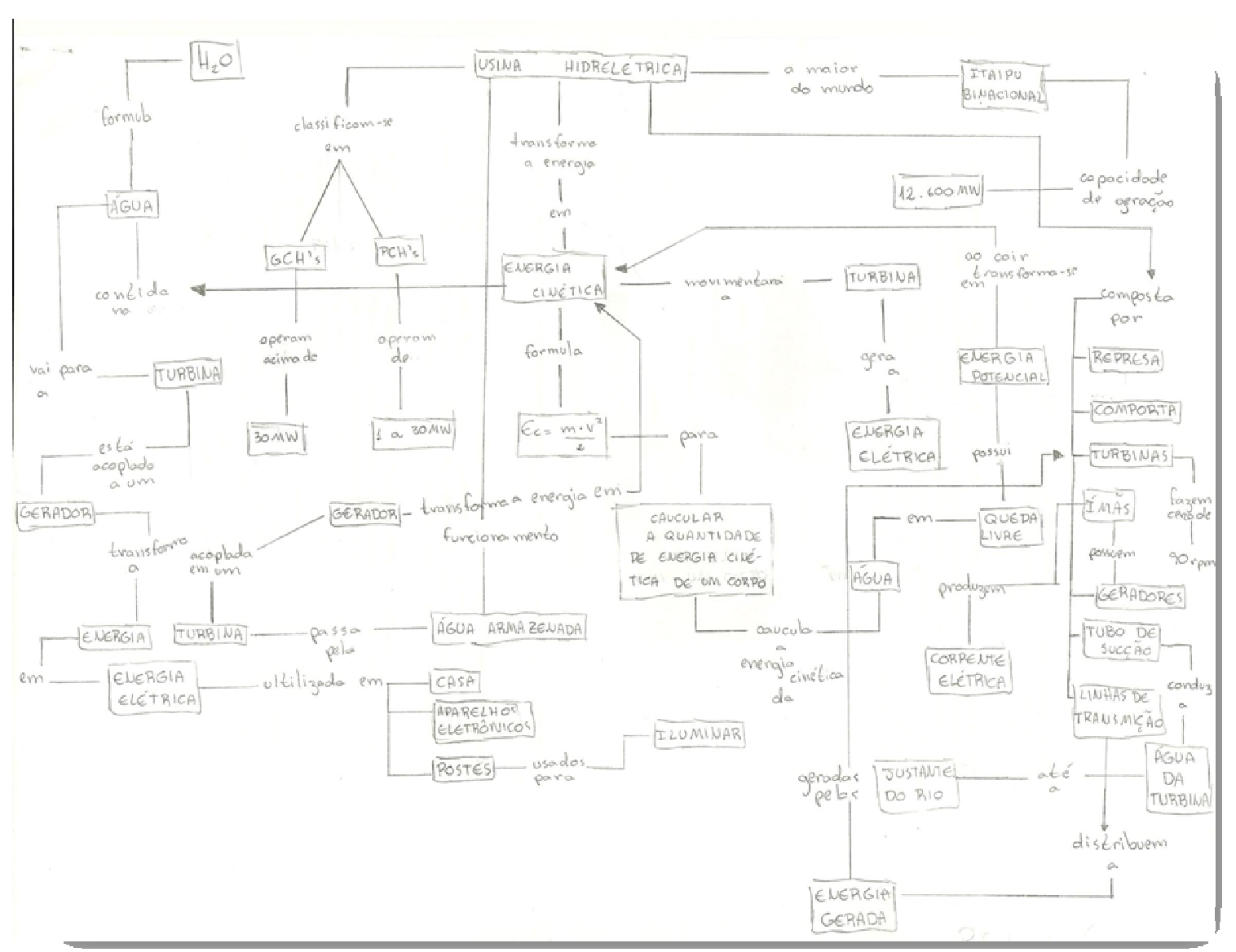

Figura 2 - Exemplo de mapa conceitual construído por um aluno ao fim da aula de mapas conceituais 
Este mapa mostra que o aluno compreendeu sua construção, pois ele apresenta hierarquias conceituais, muitas proposições corretas e conexões cruzadas, premissas básicas para a construção de mapas conceituais.

Para a verificação da ocorrência de aprendizagem significativa quando submetidos a esta forma de ensino de um tópico de FMC, existia a necessidade de saber se os alunos possuiam os subsunçores necessários. Como a teoria da aprendizagem significativa mostra, com as assimilações obliteradoras, à medida que o sujeito assimila novas informações com significados, os conceitos subsunçores se modificam. $O$ objetivo dos questionários foi o de verificar as mudanças conceituais nos subsunçores. Partiu-se da hipótese/premissa que como o conceito de energia é muito geral relativamente a suas definições e seu entendimento significativo, este se constituiria um conceito subsunçor, o conceito assimilador de novos conhecimentos.

Com este intento, portanto, elaborou-se um questionário teórico, com o objetivo de verificar qual a noção que os alunos possuíam sobre a "forma", ou constituição da energia radiante de corpos aquecidos. Isso se torna importante à medida que o conteúdo vai sendo ensinado, pois a principal mudança conceitual que há nas proposições da Física Clássica é a noção de "forma" da energia, que deixa de ser interpretada como contínua, para ser analisada como "pacotes de energia", os quanta. As perguntas que estiveram inseridas no questionário podem ser observadas em seguida:

1. Desenhe como você imagina que seja a transferência de calor entre dois corpos. Desenhe a energia sendo liberada por um corpo e sendo absorvida pelo outro, indicando, inclusive, que libera e quem recebe esta energia.

2. Explique com suas palavras como acontece a transferência de calor entre dois corpos.

3. Explique o que é calor.

4. Considere um corpo sendo iluminado por uma lâmpada que esta bem próximo a ele. Este corpo terá um aumento de temperatura após alguns segundos.

a. Explique o que irá acontecer com as partículas do corpo após o aumento de temperatura.

b. Qual é a relação entre a radiação absorvida, a vibração das partículas de um corpo, e a temperatura?

c. Qual é a relação entre energia absorvida e energia emitida pelo corpo? 
Então, este questionário foi aplicado antes das aulas de FMC e depois de concluído o trabalho para que, a partir da comparação das características contidas nessas respostas, pudéssemos inferir se os alunos mudaram suas concepções sobre a constituição da energia após o processo.

Os questionários foram aplicados antes das aulas 3 e 4 e posteriormente aplicados após as aulas 7 e 8.

Devemos salientar que a proposta não foi de ensinar conceitos de FMC, como aprendidos em nível de graduação, em Física, por exemplo, mas de mostrar aos alunos como se desenvolveu a ideia de quantização de energia no inicio do século XX, com algumas aplicações tecnológicas, como os sensores fotoelétricos em suas múltiplas utilizações.

Nosso intuito maior foi o de analisar qual a influencia de um conhecimento prévio, neste caso o conceito de energia, relacionado à Física Clássica, quando submetido a conceitos de FMC por meio da aprendizagem significativa.

\section{Metodologia de analise dos dados}

Os dados obtidos foram analisados a fim de construir um panorama da aprendizagem de cada aluno durante todo o processo. Dessa maneira, os dados foram analisados para cada aluno e da seguinte maneira:

Iniciaram-se as análises com a avaliação da mudança conceitual dos alunos com relação ao conceito de Energia. Como já detalhado anteriormente, um subsunçor específico pode aumentar sua complexidade quando ancora um novo conhecimento (assimilação obliteradora), e estes questionários deram uma idéia dessa complementação dos subsunçores, que se tornaram mais elaborados depois de conhecerem os novos conceitos.

As hipóteses a serem testadas são as de que, antes de aprenderem os conteúdos de FMC, os alunos devem manifestar em suas respostas características apenas da Física Clássica (transferência de energia contínua ou em forma de raios e explicações como conceito de energia apenas como ondas). Depois de estudarem os conceitos de quantização e outros apresentados na sequência, que estas respostas mudem, apresentando explicações que contenham os termos estudados tais como pacotes de energia, quantas, quantização e radiação de corpo negro, entre outros.

Esta mudança nos subsunçores é um dos indícios de que uma aprendizagem significativa possa ter acontecido, uma vez que os novos conceitos estão incorporados na estrutura cognitiva dos alunos, sendo possível a ligação entre os conceitos, o que verificou-se por meio de mapas conceituais.

R. B. E. C. T., vol 4, núm 3, set./dez. $2011 \quad$ ISSN - 1982-873X 
As análises foram individuais, tratando do processo de construção de conceitos de cada aluno.

Para tanto, o processo de aprendizagem de cada aluno foi analisado desde os questionários até as confecções dos mapas finais, sendo possível traçar um perfil da aprendizagem significativa de cada aluno participante.

Para a análise dessas respostas, foram utilizados os preceitos básicos da análise de conteúdo (Bardin, 1977), principalmente por se tratar de uma técnica de análise de textos por meio da desconstrução destes, a fim de descobrir os seus sentidos principais. Segundo a autora, a análise de conteúdo é:

“[...] um conjunto de técnicas de análise das comunicações que utiliza procedimentos sistemáticos e objetivos de descrição do conteúdo das mensagens". Tais procedimentos são criteriosos, com muitos aspectos observáveis, mas que colaboram bastante no desvendar dos conteúdos de seus documentos." (Bardin, 2002, p.38)

Constitui o material de análise os questionários I e II e as respostas dos alunos para estes. As respostas que apresentavam os mesmos preceitos foram agrupadas em categorias, como descreve Bardin:

[...] uma operação de classificação de elementos constitutivos de um conjunto, por diferenciação e, seguidamente, por reagrupamento segundo o gênero (analogia), com os critérios previamente definidos. As categorias são rubricas ou classes, as quais reúnem um grupo de elementos (unidades de registro, no caso da análise de conteúdo) sob um título genérico, agrupamento esse efectuado em razão dos caracteres comuns desses elementos (BARDIN, 1977, p. 117).

Dentre as orientações deste referencial, está a análise categorial, por meio da construção de grelhas de análise, nas quais serão agrupadas as categorias definidas e as Unidades de Análise (UA) encontradas para cada categoria, afim de construir uma interpretação dos dados a partir do referencial adotado - neste caso, os subsunçores.

Com estas orientações metodológicas, foram criadas duas categorias nas quais as respostas às questões propostas nos dois questionários de cada aluno foram agrupadas, sendo elas:

C1: Respostas que apresentam bases conceituais apenas com conceitos clássicos e/ou explicações para os fenômenos com bases teóricas características da Física Clássica (subsunçores clássicos); 
C2: Respostas que apresentam bases conceituais quânticas, ou seja, que se utilizam de conceitos quânticos em suas explicações, tais como quantização, pacotes de energia, energia quantizada, etc. (subsunçores quânticos).

Como continuação da análise dos dados, os mapas conceituais foram idealizados com o objetivo da interpretação da aprendizagem por parte dos alunos. Inicialmente foi ensinada a construção dos mapas conceituais e posteriormente (ao término das aulas de quantização da energia) pediu-se a estes alunos que construíssem individualmente um mapa conceitual referente a todas as aulas apresentadas. Para tanto, pediu-se que utilizassem de suas anotações e que escolhessem os conceitos mais apropriados para a realização do mesmo.

Os mapas construídos pelos alunos foram analisados segundo os objetivos a seguir:

- A ligação entre conceitos físicos deve estar correta, ou seja, os conceitos para estarem ligados devem realmente ter algum tipo de relação (relações válidas);

- A frase de ligação referente aos conceitos deve estar coerente com a real relação entre os conceitos físicos (proposições coerentes);

- A ordenação dos conceitos dentro do mapa devem seguir o grau de especificidade do conceito, ou seja, conceitos mais gerais no topo do mapa, e quanto mais especifico mais abaixo deve estar o conceito no mapa (hierarquias válidas);

- Os exemplos devem ter relações significativas entre os conceitos (exemplos válidos);

- As conexões cruzadas devem possuir coerência e devem ter caminhos distintos fazendo ligações entre estruturas hierárquicas mais complexas dentro do mapa (conexões cruzadas válidas).

\section{Analise dos dados}

A análise se inicia com a categorização das respostas obtidas por meio dos questionários que foram aplicados antes e depois das aulas de FMC. Em seguida analisaram-se os mapas conceituais de cada aluno. São mostrados e discutidos detalhadamente nesta análise os trabalhos com dois alunos de um total de quinze que participaram da pesquisa 
Aluno 1

Questionário I

\begin{tabular}{|c|c|c|}
\hline Categoria & \multicolumn{1}{|c|}{ Unidades de Análise } & \multicolumn{1}{|c|}{ Interpretação } \\
\hline $\mathrm{C1}$ & $\begin{array}{c}\text { Porque a lâmpada } \\
\text { transfere ondas } \\
\text { eletromagnéticas que contém } \\
\text { energia para o corpo. }\end{array}$ & $\begin{array}{l}\text { A presença da idéia de } \\
\text { onda eletromagnética é um } \\
\text { indício de que o aluno tinha um } \\
\text { conhecimento prévio ainda } \\
\text { baseado em idéias clássicas, o } \\
\text { que era esperado para o } \\
\text { primeiro questionário }\end{array}$ \\
\hline C2 & Não há respostas \\
pertencentes à categoria C2.
\end{tabular}

Quadro 2 - Análise do questionário I do aluno 1

\section{Questionário II}

\begin{tabular}{|c|c|c|}
\hline Categoria & Unidades de Análise & Interpretação \\
\hline C1 & $\begin{array}{l}\text { Calor é a energia } \\
\text { transferida de um corpo para } \\
\text { outro. }\end{array}$ & $\begin{array}{l}\text { O aluno faz a relação } \\
\text { correta com energia e calor, mas } \\
\text { nada diz quanto a natureza } \\
\text { dessa energia. }\end{array}$ \\
\hline C2 & $\begin{array}{l}\text { Um corpo transmite } \\
\text { calor, em forma de blocos } \\
\text { chamados fótons, o corpo que } \\
\text { absorve a radiação aumenta a } \\
\text { agitação das partículas e da } \\
\text { temperatura. } \\
\text { A absorção da radiação } \\
\text { com que a agitação } \\
\text { aumente. } \\
\text { Quanto maior a } \\
\text { freqüência das partículas, mais } \\
\text { se aproxima da luz visível. }\end{array}$ & $\begin{array}{l}\text { Mostra a mudança da } \\
\text { idéia de energia, que passa a ser } \\
\text { interpretada pelo aluno como } \\
\text { quantizada. O aluno ainda faz } \\
\text { relações corretas entre os } \\
\text { conceitos de absorção de } \\
\text { radiação com o aumento de } \\
\text { temperatura e com a freqüência } \\
\text { da radiação emitida. } \\
\text { Obliteração } \\
\text { subsunçor. }\end{array}$ \\
\hline
\end{tabular}

Quadro 3 - Análise do questionário II do aluno 1 
A análise dos questionários do aluno 1 mostra que ele tinha, antes das aulas de FMC, um conceito de energia correto, como podemos observar em C1 do questionário I, em que o aluno expressou a ideia de que as ondas eletromagnéticas transportam energia de um corpo para outro. Já em C2 do questionário II observamos uma mudança conceitual quanto ao significado de energia emitida pelo corpo, desta vez com significados quânticos. Interpretamos este fato como uma evidência de aprendizagem significativa, pelo fato de que houve mudança no conceito subsunçor "energia", no sentido de que ficou mais significativo ao aluno quando incorporou as abordagens quânticas.

Ainda com relação ao questionário II, o aluno soube destacar corretamente a relação de temperatura com o grau de agitação das partículas de um corpo, e podemos observar também que soube explicar que a emissão de energia depende deste grau de agitação, destacando a natureza da radiação, em que cita que o calor é emitido em blocos denominados fótons. Por existir ai um raciocínio correto do aluno que fez estas relações corretas, e que também notamos que foi apresentado diferentemente do material exposto pelo professor, podemos inferir um indicio de aprendizagem significativa. Este indício é baseado no que diz respeito ao conhecimento conotativo do aluno, aquele conhecimento que traz consigo interpretações do próprio aluno, e quando o aluno externaliza o conhecimento desta forma, ele nos mostra que obteve aprendizagem significativa. 


\section{Mapa conceitual do aluno 1}

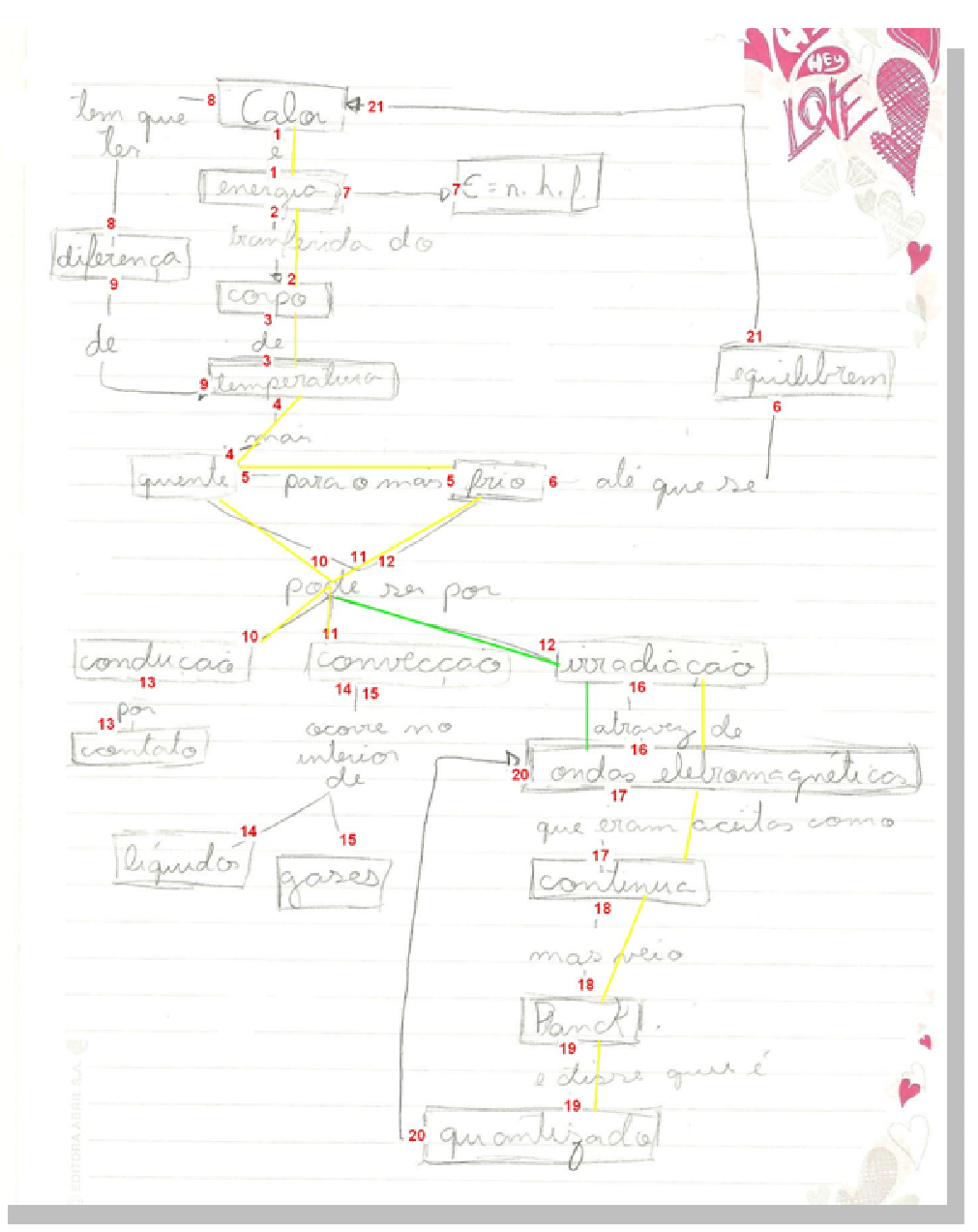

Figura 3 - Análise do mapa conceitual confeccionado pelo aluno 1

Podemos notar no mapa conceitual duas hierarquias e uma conexão cruzada, procedimentos muito importantes para indícios de aprendizagem significativa. Podemos observar, também, relações importantes com o subsunçor "energia" de conceitos de quantização de energia.

Os segmentos das linhas amarelas representam as estruturas hierárquicas e, como podemos notar, este mapa apresenta duas estruturas. A primeira aborda os conceitos de "calor" e "energia" como os conceitos mais gerais e são seguidos, mais abaixo no mapa, de suas especificações. O aluno reconhece que o "calor" é uma forma de "energia" e diz como acontece a transferência de calor de um corpo para outro. Mais abaixo no mapa observamos os tipos de transferência de calor, e uma ramificação chegando ao conceito de "ondas eletromagnéticas", em que este, por sua vez, é especificado segundo conceitos quânticos, mostrando que as ondas eletromagnéticas são emitidas por um corpo de maneira quantizada. 
A linha verde nos mostra uma conexão cruzada entre estas duas hierarquias. Interpretamos esta conexão como um indicio de que houve relações de conceitos clássicos com conceitos quânticos, além do mais, aprendizagem significativa.

Apesar da falta de proposições no mapa do aluno 1, de acordo com as analises, podemos acreditar que a aprendizagem foi satisfatória, mostrando a possibilidade de ligação de conceitos clássicos a conceitos de FMC a partir de uma aprendizagem significativa.

\section{Aluno 2}

\section{Questionário I}

\begin{tabular}{|c|c|c|}
\hline Categoria & Unidades de Análise & Interpretação \\
\hline $\mathrm{C} 1$ & $\begin{array}{l}\text { Figura } 23 \\
\text { Porque a lâmpada } \\
\text { libera ondas eletromagnéticas } \\
\text { que, em contato com o objeto, } \\
\text { aumenta a temperatura até } \\
\text { haver equilíbrio. } \\
\text { Calor é a energia } \\
\text { transferida de um corpo para } \\
\text { outro. }\end{array}$ & $\begin{array}{l}\text { Tanto a figura quanto a } \\
\text { fala do aluno apresentam } \\
\text { somente aspectos clássicos. } \\
\text { Corretamente explicados, mas } \\
\text { ainda assim clássicos. }\end{array}$ \\
\hline $\mathrm{C} 2$ & $\begin{array}{c}\text { Não há respostas } \\
\text { pertencentes à categoria C2 }\end{array}$ & \\
\hline
\end{tabular}

Quadro 4 - Análise do questionário I do aluno 2

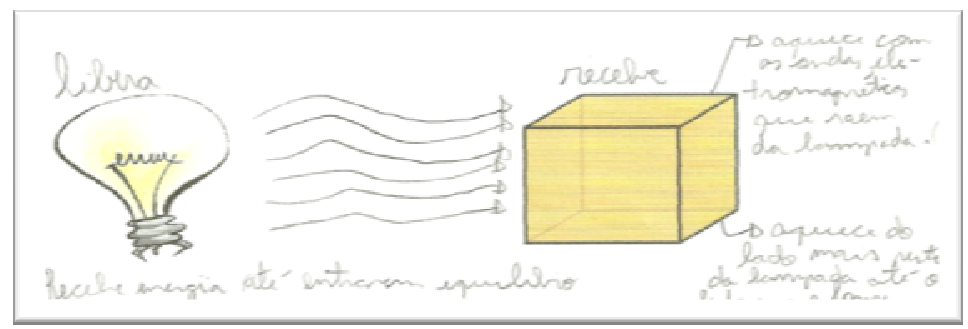

Figura 4 - Desenho do aluno 2 em resposta ao questionário I 
Questionário II

\begin{tabular}{|c|c|c|}
\hline Categoria & Unidades de Análise & Interpretação \\
\hline C1 & $\begin{array}{l}\text { Calor é a energia } \\
\text { transferida de um corpo de } \\
\text { maior temperatura para um } \\
\text { corpo de menor temperatura. }\end{array}$ & $\begin{array}{l}\text { O aluno mostra } \\
\text { compreensão com relação aos } \\
\text { aspectos relativos } \\
\text { transferência de calor e faz a } \\
\text { relação com a energia, mas não } \\
\text { incorpora significados quânticos. }\end{array}$ \\
\hline $\mathrm{C} 2$ & $\begin{array}{l}\text { Essa radiação é a } \\
\text { eletromagnética. O corpo emite } \\
\text { essa radiação que é um conjunto } \\
\text { de fótons que será absorvido por } \\
\text { outro corpo, aumentando sua } \\
\text { temperatura. } \\
\text { O corpo absorve a } \\
\text { radiação, suas partículas } \\
\text { começam a vibrar na mesma } \\
\text { freqüência, fazendo com que } \\
\text { sua temperatura aumente. } \\
\text { Figura } 24 \text {. }\end{array}$ & $\begin{array}{l}\text { Faz relações corretas } \\
\text { incluindo conceitos quânticos } \\
\text { como os fótons e faz referencia } \\
\text { da relação da absorção de } \\
\text { energia de uma determinada } \\
\text { freqüência com a freqüência de } \\
\text { vibração das partículas de um } \\
\text { corpo e que isso faz com que } \\
\text { aumente a temperatura do } \\
\text { corpo. } \\
\text { Obliteração do } \\
\text { subsunçor. }\end{array}$ \\
\hline
\end{tabular}

Quadro 5 - Análise do questionário II do aluno 2

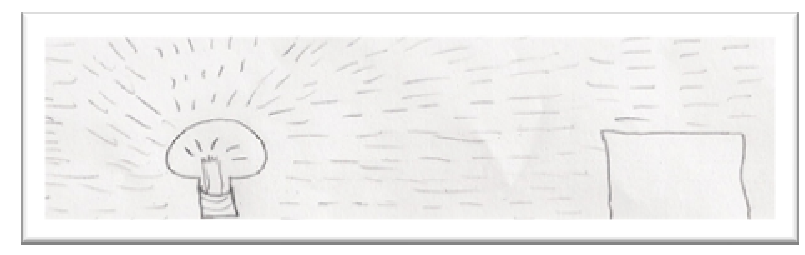

Figura 5 - Desenho do aluno 2 em resposta ao questionário II

Com relação a analise dos questionários do aluno 2, podemos notar que houve obliteração do conceito subsunçor energia. As respostas do questionário I não fazem referencia alguma sobre conceitos de FMC, mas apenas nos mostra a relação correta entre os conceitos de energia e calor. Após as aulas sobre a quantização de energia, nas respostas do questionário II, podemos observar que o aluno consegue explicar o conceito de energia com outros significados assimilados (C2) durante as aulas, além dos significados já aprendidos (C1). Podemos inferir sobre este fato que o 
aluno conseguiu assimilar corretamente os conceitos quânticos nos mostrando modificações significativas de seu subsunçor energia, um indicio que ocorreu aprendizagem significativa.

Outro objetivo que conseguimos atingir com o aluno 2 foi o de que conseguiu assimilar os conceitos de FMC aos conceitos que já existia em sua estrutura cognitiva que faziam referência aos conceitos clássicos, como podemos perceber nas obliterações ocorridas com o conceito de energia. Antes trazia significados como "calor é a energia transferida de um corpo para outro". Mais significados foram assimilados como "essa radiação é a eletromagnética [...] que é um conjunto de fótons". Essa foi umas das evidencias de obliteração do subsunçor em que pudemos inferir indícios de que houve aprendizagem significativa de conceitos de FMC. 


\section{Mapa conceitual do aluno 2}

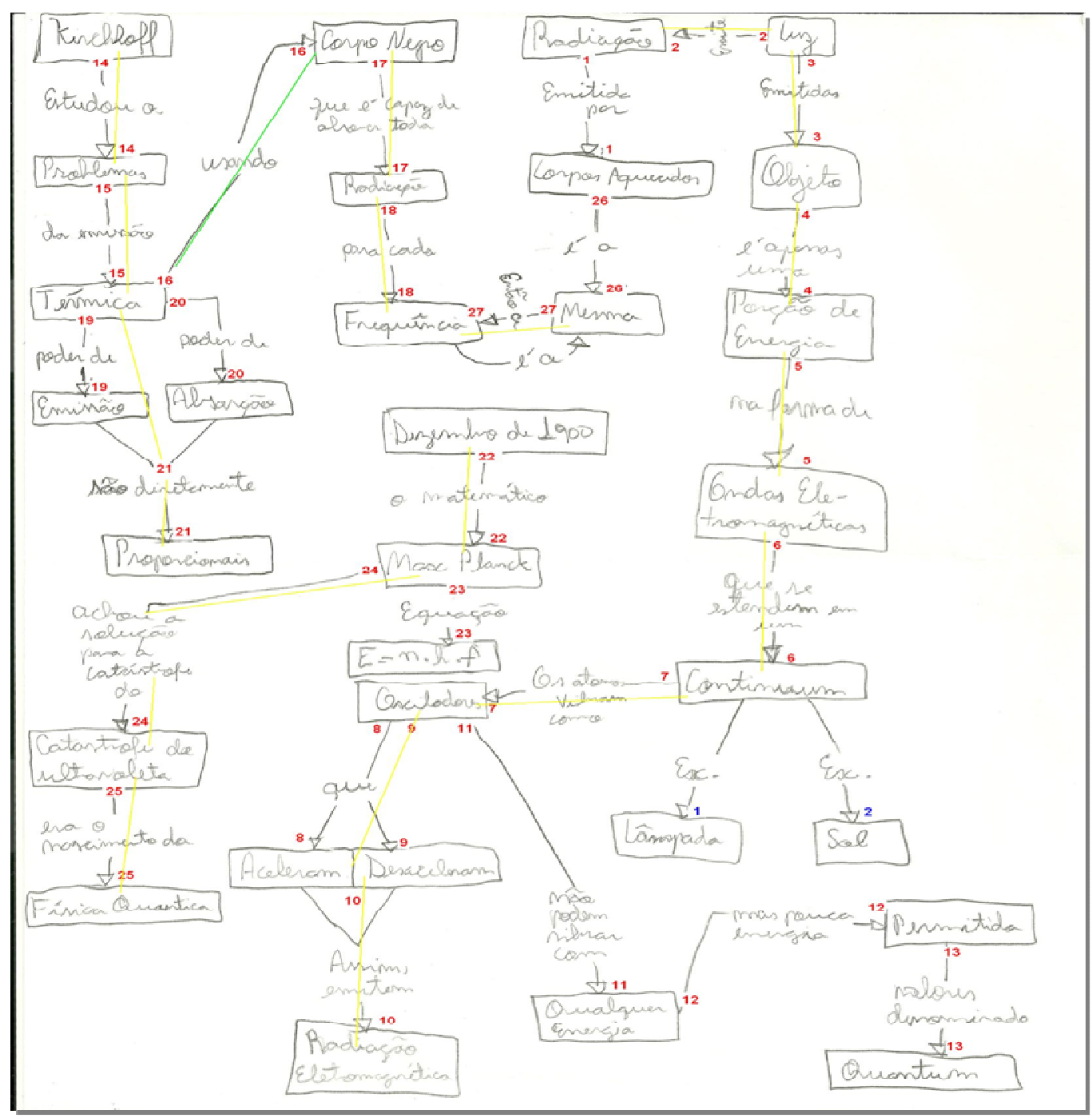

Figura 8 - Análise do mapa conceitual confeccionado pelo aluno 2

Um número significativo de proposições e hierarquias coerentes foram encontradas nesse mapa conceitual. Comecemos por analisar as quatro hierarquias significativas encontradas.

A primeira hierarquia inicia com um conceito mais geral, seu subsunçor, o conceito de radiação, como podemos observar na figura. O aluno começa por especificar este conceito de radiação relacionando com os conceitos de energia e ondas eletromagnéticas. Como nesta frase que interpretamos: "radiação de luz emitida por objetos é apenas uma porção de energia na forma de ondas eletromagnéticas que se estendem em um contínuo, os átomos vibram como osciladores que aceleram e desaceleram emitindo radiação eletromagnética, mas não podem 
vibrar com qualquer energia, mas algumas poucas energias permitidas, valores denominados quantum". Essa hierarquia nos mostra que o aluno soube entender o assimilar os conceitos corretos quanto a emissão de radiação.

A segunda hierarquia nos mostra que o aluno relacionou ao cientista Kirchhoff os estudos com os problemas da emissão de radiação térmica mostrando sua descoberta de que o poder de emissão é igual ao poder de absorção, ou melhor, são diretamente proporcionais. Esta estrutura hierárquica faz uma conexão cruzada com a terceira estrutura que encontramos, a que tem por conceito mais geral o de corpo negro.

A quarta hierarquia esta relacionada à descoberta da quantização da energia, por Max Planck, em dezembro de 1900.

Por todas as hierarquias analisadas e a única conexão cruzada, podemos observar outro indicio de aprendizagem significativa por parte do aluno 4 e juntamente com a obliteração de seu conceito subsunçor (indicio observado nos questionários) podemos inferir que atingimos nosso objetivo com este aluno. Observamos seu aprendizado referente a conceitos de FMC a partir dos conceitos clássicos.

\section{Conclusão}

De acordo com a analise verificada, podemos concluir de uma forma segura que existem possibilidades de inserção de FMC no EM a partir das limitações da FC, e que, principalmente os alunos podem aprender significativamente estes conhecimentos.

A abordagem conferida por esta metodologia nos mostra que é possível gerar um material com potencial significativo levando em consideração a organização dos conceitos que devem ser ensinados aos alunos. Os conceitos que devem ser apresentados são os de maior generalidade, para assim, serem especificados por outros conceitos, como seguimos durante o desenvolvimento das aulas. Os conceitos de energia e calor foram apresentados, inicialmente, para que assim fossemos progressivamente especificando-os ao longo das aulas, com o objetivo de inserção de conceitos de quantização de energia a partir dos limites da FC.

Esta forma de abordagem nos forneceu um material de aula potencialmente significativo, umas das premissas básicas para a aprendizagem significativa. Assim, analisamos as obliterações sofridas pelo subsunçor energia, sendo que investigamos a ideia que os alunos tinham antes das abordagens quânticas e depois. A análise nos mostrou que realmente houve uma obliteração deste conceito subsunçor, isso quer dizer que o conceito de energia se modificou, incorporando novos significados, os de quantização (FMC). Este foi um dos primeiros indícios para inferirmos que houve aprendizagem significativa. 
A obliteração do conceito é importante na perspectiva da aprendizagem significativa, pois quando este assimila novos conceitos, estes novos deixam resíduos no subsunçor, modificam os significados do subsunçor, ou ainda, deixam os subsunçores com mais significados. Quando o individuo tem o esquecimento destes conceitos mais específicos, que foram incorporados pelo subsunçor, a lembrança ou a reaprendizagem é facilitada pelos resíduos deixados.

E ainda, outro indício de aprendizagem significativa que obtivemos, foi pela analise dos mapas conceituais que nos mostrou, principalmente, estruturas organizadas de conceitos, ou seja, estruturas hierárquicas e conexões cruzadas entre elas de conceitos assimilados pelos alunos durantes as aulas de FMC.

Estas estruturas são modelos idealizados das estruturas cognitivas dos alunos, por isso, se elas nos mostram organização, hierarquia, diferenciação progressiva e reconciliação integrativa, quer dizer que aluno aprendeu de forma coerente e, principalmente, significativa.

Um fator importante que devemos citar é o de que o aluno, quando aprende significativamente, não externaliza seus conhecimentos de forma literal ao material assimilado e sim, na maioria das vezes, de forma genérica. O que queremos dizer com externalização de forma genérica, é que o aluno nos mostra o conteúdo que aprendeu de forma diferente do original, pois ele atribui seus próprios significados aos conceitos assimilados. Na maioria das vezes, quando analisamos os mapas e os questionários, encontramos estes tipos de externalizações genéricas, proposições não literalizadas em relação ao material apresentado aos alunos; de tal maneira que isto nos fornece mais uma evidencia de que realmente ocorreu aprendizagem significativa.

Devemos salientar também que o objetivo deste trabalho não foi o de ensinar para alunos de ensino médio todas as idéias da mecânica quântica ou da FMC, mas sim, tentamos mostrar que por meio dos limites da FC é possível uma inserção de FMC, como a que fizemos. Pode-se pensar em outros conceitos ainda, como por exemplo, a partir dos limites da mecânica clássica pode se inserir conceitos e idéias do conteúdo de teoria da relatividade, tomando como um desses limites o problema da velocidade de um corpo próxima a velocidade da luz.

Enfim, mostramos como os referenciais nos ajudaram no momento das aplicações das aulas, no momento da preparação das aulas e também para a análise dos dados. Estes puderam nos mostrar que de certa forma é possível a inserção de FMC no EM, quando estes assuntos são inseridos no contexto das limitações dos conceitos clássicos como solução e continuidade do estudo da Física; e que além do mais, pode mudar a concepção que os alunos têm sobre tal ciência, tornando-se um estudo prazeroso, curioso e, principalmente um estudo atual. 


\section{Referências}

Ausubel, D. P. The psychology of meaningful verbal learning. New York: Grune \& Stratton, 1963. Ausubel, D.P. ; Novak, J.D. e Hanesian, H. Psicologia educacional. Interamericana: Rio de Janeiro, 1980.

Ausubel, D. Aquisição e retenção de conhecimento: uma perspectiva cognitiva. Platano edições técnicas: Lisboa, 2002.

Bardin, L. Análise de Conteúdo. Tradução de Luís Antero Reto e Augusto Pinheiro Lisboa: Edições 70, 1997.

Brasil. Ministério da Educação. PCN+ Ensino Médio: Orientações Complementares aos Parâmetros Curriculares Nacionais para o Ensino Médio. Ciências da Natureza, Matemática e suas tecnologias. Brasília, 2002

Chalmers, A. O que é a ciência, afinal? Ed. Brasiliense: São Paulo, 1993.

Ferreira, C. Como funciona uma usina hidrelétrica. Disponível em

<http://www.infoescola.com/fisica/como-funciona-uma-hidreletrica>Acesso em 02/04/2010

Masini, E. F. S.; Moreira, M. A. Aprendizagem Significativa: Condições para a ocorrência e lacunas que levam ao comprometimento. São Paulo: Vetor. 2008.

Moreira, M.A. e Masini, E.F.S. Aprendizagem Significativa: A teoria de David Ausubel. Editora Moraes: São Paulo, 1982.

Novak, J.D. Uma teoria de educação. Ed. Pioneira:São Paulo, 1981.

Novak, J.D., Gowin, B. Aprendiendo a aprender. Ediciones Martínez Roca: Barcelona, 1988.

Ostermann, F.; Cavalcanti, C. Física Moderna e Contemporânea no ensino médio: elaboração de material didático, em forma de pôster, sobre partículas elementares e interações fundamentais. Cad.Cat.Ens.Fís., v. 16, n. 3: p. 267-286, dez. 1999.

Ostermann, F. Moreira, M. A. Uma revisão bibliográfica sobre a área de pesquisa "Física Moderna e Contemporânea no Ensino Médio. Revista Investigação em Ensino de Ciências do Instituto de Física da Universidade Federal do Rio Grande do Sul, Porto Alegre, v. 05, n. 01, mar. 2000. Disponível em <HTTP://www.if.ufrgs.br/public/ensino> Acesso em 15/03/2010.

Terrazzan, E.A. Perspectivas para a inserção de Física Moderna na Escola Média. 1994, 241 f. Tese (Doutorado em Educação) - Faculdade de Educação, Universidade de São Paulo, São Paulo. 
Alex Lino. Universidade Estadual de Maringá (UEM). Programa de Pós-Graduação em Educação para a Ciência e a Matemática (PCM). Mestre em Educação Para a Ciência e o Ensino de Matemática pela Universidade Estadual de Maringá (UEM). alexlinopp@hotmail.com Polônia Altoé Fusinato. Universidade Estadual de Maringá (UEM). Programa de Pós-Graduação em Educação para a Ciência e a Matemática (PCM). Doutor em Educação pela Universidade de São Paulo (USP). altoepoly@gmail.com 